\title{
PEMODELAN SMART HOUSE SYSTEM BERBASIS HUMAN MACHINE INTERFACE MENGGUNAKAN SOFTWARE LABVIEW DAN MIKROKONTROLER ARDUINO
}

\author{
*Munadi, Bob Aditiyo, Moch. Ariyanto, Norman Iskandar \\ Lab. Robotika, Otomasi dan Komputasi, Departemen Teknik Mesin, Universitas Diponegoro \\ Jl. Prof. Sudharto, SH., Tembalang-Semarang, 50275, Telp. 0247460059 \\ *E-mail: munadi@undip.ac.id
}

\begin{abstract}
ABSTRAK
Penghematan energi listrik menjadi trend penelitian dibidang energi. Salah satu usaha penghematan energi listrik untuk rumah tangga salah satunya adalah aplikasi smart house systems dimana saat ini sedang dikembangkan banyak pihak. Hal ini dikarenakan smart house systems dapat memberikan rasa kemudahan, kenyamanan, keamanan, selain dapat menghemat penggunaan energi listrik. Smart house systems merupakan sebuah sistem otomasi berbasis komputer yang berlangsung secara otomatis dan terprogram melalui komputer yang diaplikasikan pada peralatan rumah. Dalam perkembangannya, smart house systems didukung dengan aplikasi Human Machine Interface (HMI) sebagai user interface untuk mempermudah pengunaanya. Pada penelitian ini, telah dibuat model smart house system yang terintergrasi dengan HMI (LabView) untuk memonitor keadaan yang ada di depan rumah dengan CCTV, mengontrol pintu gerbang, lampu-lampu, atap jemuran, alarm kebocoran gas, serta alarm pencuri. Metode untuk sistem jaringan yang digunakan pada smart house systems ini menggunakan main server untuk penyimpanan program dan sebagai sistem kendali. Dengan menggunakan smart house systems, berdasarkan estimasi perhitungan yang dilakukan, dapat menghemat energi listrik sebesar $27,2 \%$ karena semua peralatan elektronik yang ada di rumah dapat diatur jam kerjanya menggunakan HMI.
\end{abstract}

Kata kunci: smart house systems, penghematan energi, HMI, LabView, Arduino

\section{PENDAHULUAN}

Smart house adalah sebuah sistem berbasis komputer yang akan memberikan rasa kenyamanan, kemudahan, keamanan, dan adanya penghematan energi, yang berlangsung secara otomatis dan terprogram melalui komputer yang diaplikasikan untuk rumah tinggal. Perkembangan smart house di negara Eropa dan Amerika cukup pesat. Hal ini salah satunya tidak lepas dari keterbatasan sumber energi listrik, sehingga kita harus benar-benar efisien dalam penggunaan energi tersebut. Selain itu, faktor kenyamanan kadang menjadi pertimbangan prioritas pengembangan smart house saat ini.

Dalam perkembangannya smart house didukung dengan Human Machine Interface (HMI) untuk mempermudah pengunaanya [1]. HMI adalah sebuah interface atau tampilan penghubung antara manusia dengan mesin sehingga memudahkan dalam memonitor [2]. HMI dapat diartikan sebagai user interface dan sistem kontrol untuk aplikasi otomasi sehingga pada penelitian ini, peneliti ingin mengembangkan model smart house yang terintegrasi dengan HMI demi kenyamanan pada sebuah model rumah yang mengaplikasikan smart house systems. Tujuan penggunaan HMI pada smart house pada penelitian ini adalah memonitor keadaan yang ada di depan rumah dengan Closed Circuit Television (CCTV), mengontrol pintu gerbang, mengontrol lampu-lampu dan beberapa peralatan rumah tangga lainnya dengan sistem kontrol yang baik.

Untuk membuat HMI diperlukan software dalam mendesainnya, dan software yang digunakan salah satunya adalah LabVIEW. LabVIEW adalah salah satu bahasa pemograman komputer grafik yang menggunakan icon-icon sebagai pengganti teks dalam membuat aplikasi. Berbeda dengan pemograman berbasis teks dimana instruksi-instruksi menentukan eksekusi program, LabVIEW merupakan pemograman aliran data dimana aliran data menentukan eksekusi dari program yang dapat diaplikasikan untuk pengaturan efisiensi energi [3].

Dalam pemodelan smart house ini dibutuhkan sebuah mikrokontroler untuk mengatur sistem kerjanya, dan mikrokontroler yang digunakan berupa Arduino Mega 2560. Arduino merupakan sebuah platform komputasi fisik (physical computating) yang open source pada board input output sederhana. Platform komputasi fisik disini adalah sebuah sistem fisik yang interaktif dengan penggunaan software dan hardware yang dapat mendeteksi dan merespons situasi dan kondisi yang ada di dunia nyata. Dengan pemodelan smart house ini, maka akan diperoleh data perbandingan efisiensi penggunaan energi listrik untuk rumah tangga yang umumnya dapat diterapkan di Indonesia.

\section{Smart House System}

\subsection{Perkembangan Smart House System}

Beberapa peneliti memiliki definisi smart house berbeda-beda, tergantung sudut pandang masing-masing. Nicola King dari Intertek Research \& Testing Center mendefinisikan smart house sebagai sebuah hunian yang dilengkapi dengan jaringan komunikasi yang menghubungkan berbagai layanan dan peralatan elektronik, dan memungkinkan 
untuk dipantau, diakses dan dikendalikan dari jarak jauh [4]. Jadi smart house adalah rumah yang memenuhi aspek comfort (kenyamanan), safety (keamanan), efficiency (efisien), dan connectivity (terhubung) [5]. Contoh smart house system yang ada ditunjukan pada Gambar 1 .

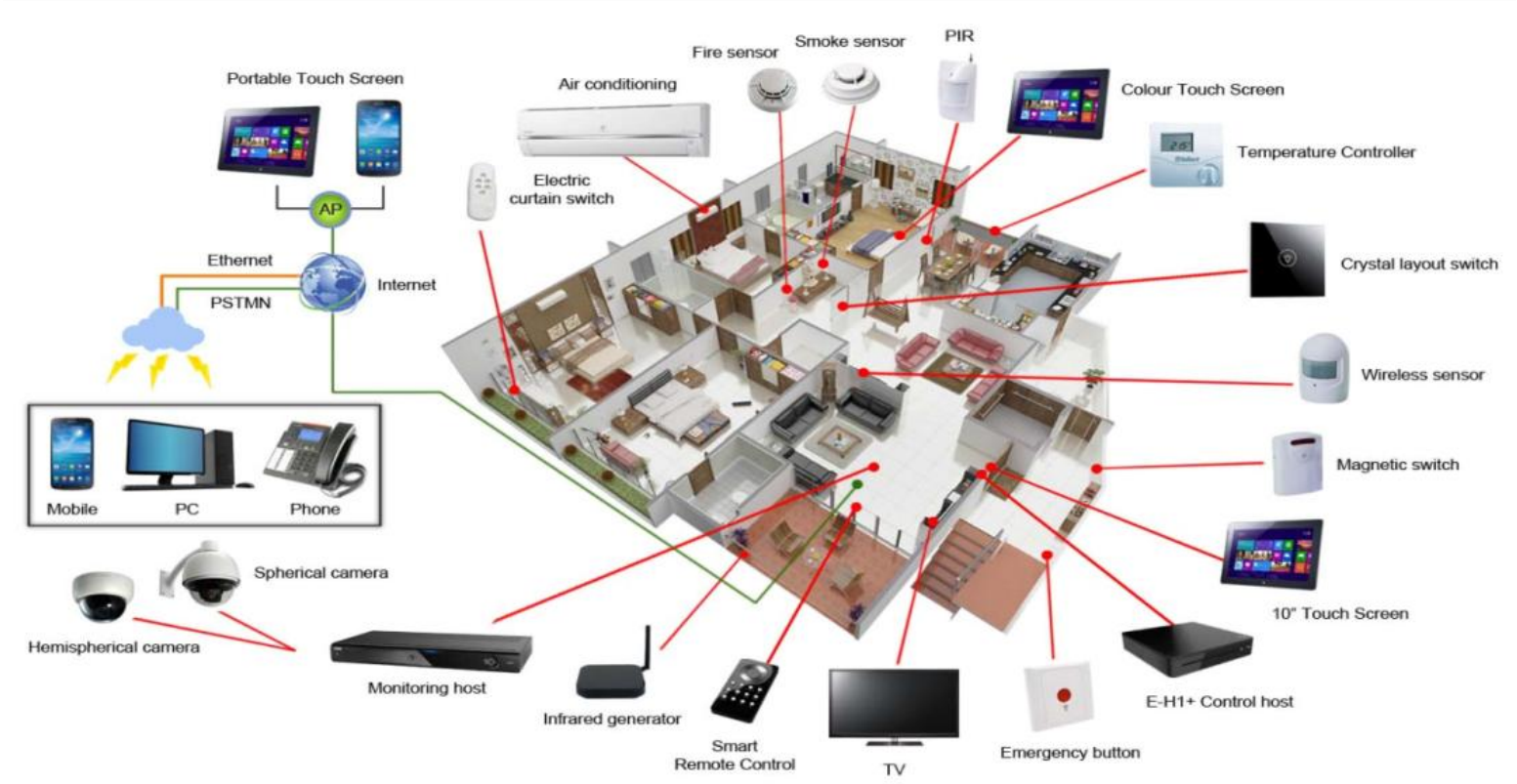

Gambar 1. Smart house system [6]

Memang belum banyak yang mengaplikasikan smart house karena banyak aspek yang harus dipertimbangkan, tetapi terdapat beberapa ilmuan yang sudah mulai mendesain konsep smart house untuk masa depan [7]. Smart house yang didesain ilmuan bukan berarti hanya bekerja serba otomatis, tetapi harus memberikan rasa aman juga menjamin kenyamanan penghuninya [8]. Banyak aspek yang dapat diatur pada smart house mulai dari sistem telekomunikasi sampai dengan sistem kamera untuk memonitor kondisi rumah sampai dengan penghematan energi [9]. Dengan smart house, sangat memungkinkan seseorang yang berada di luar kota bisa mengendalikan hampir semua bagian rumah, cukup melalui ponsel. Diantaranya adalah memastikan kulkas tetap hidup, memastikan peralatan home theatre pada kondisi mati, kamera pengawas tetap aktif, mobil masih parkir di garasi, menyalakan lampu dan mematikannya di pagi hari, bahkan membuka jendela dan gordin di pagi dan menutupnya kembali di sore hari.

\subsection{Fitur Model Smart House System}

Agar penelitian ini bersifat ready to used, maka smart house akan dibuat modelnya berupa maket dari ukuran rumah sebenarnya 10x17 m dengan skala 1:35. Pada smart house terdapat dua kamar tidur, kamar mandi, ruang tamu, ruang keluarga, gerbang, dan taman seperti yang ditunjukkan pada Gambar 2.

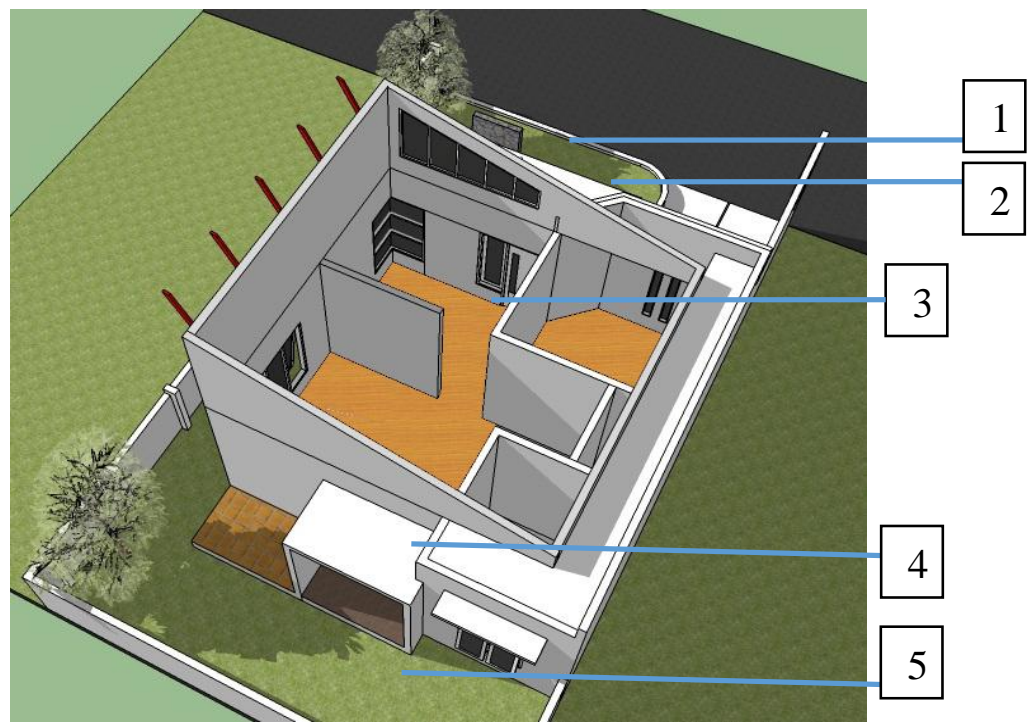

Keterangan fitur yang dikontrol :

1. Pintu gerbang otomatis dan CCVT

2. Lampu taman dan lampu teras otomatis

3. Lampu ruang keluarga otomatis

4. Atap jemuran otomatis

5. Pompa air otomatis

Gambar 2. Desain model smart house. 
Selanjutnya pada model smart house akan dilakukan proses pendesainan maket rumah dan tata letak komponen yang akan digunakan pada smart house ini. Pada tahapan pembuatan desain ini digunakan software SolidWorks. Pada SolidWorks desain ini dibuat dengan sudut pandang yang jelas yaitu sudut pandang isometric. Hal ini dilakukan agar dalam pembuatan model ini lebih jelas dan mengurangi kesalahan dalam proses pembuatannya. Pada proses desain pada software digunakan juga fitur sheet metal sehingga tampilan dari desain menyerupai bentuk aslinya dengan memasukkan material properties. Rencana desain model smart house dan tata letak komponen ditunjukkan pada Gambar 3.

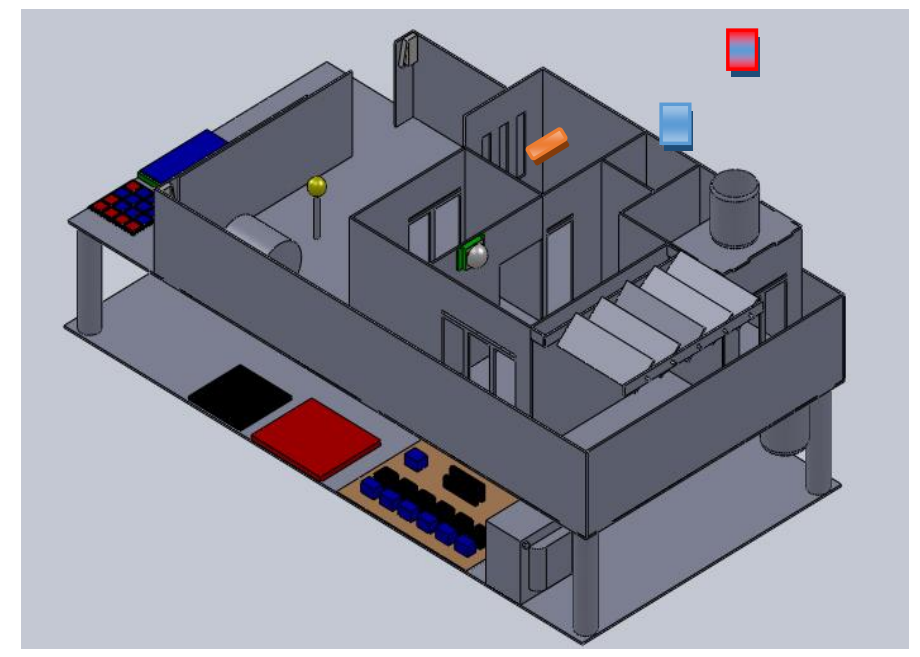

Gambar 3. Model smart house.
Berikut ini komponen yang digunakan untuk model smart house :

1. Keypad $4 x 4$

2. $L C D$

3. Motor penggerak

4. Lampu

5. Limitswitch

6. Sensor $L D R$

7. Sensor gerak

8. Tandon atas

9. Tandon bawah

10. Driver motor

11. Mikrokontroler

12. Driver lampu

13. Power supply

14. Jemuran otomatis

15. Laser dan sensor LDR

16. CCTV

Adapun sistem elektronis model smart house ini terdiri atas beberapa komponen elektronika yang disusun membentuk sebuah diagram desain hardware dan ditunjukkan pada Gambar 4.

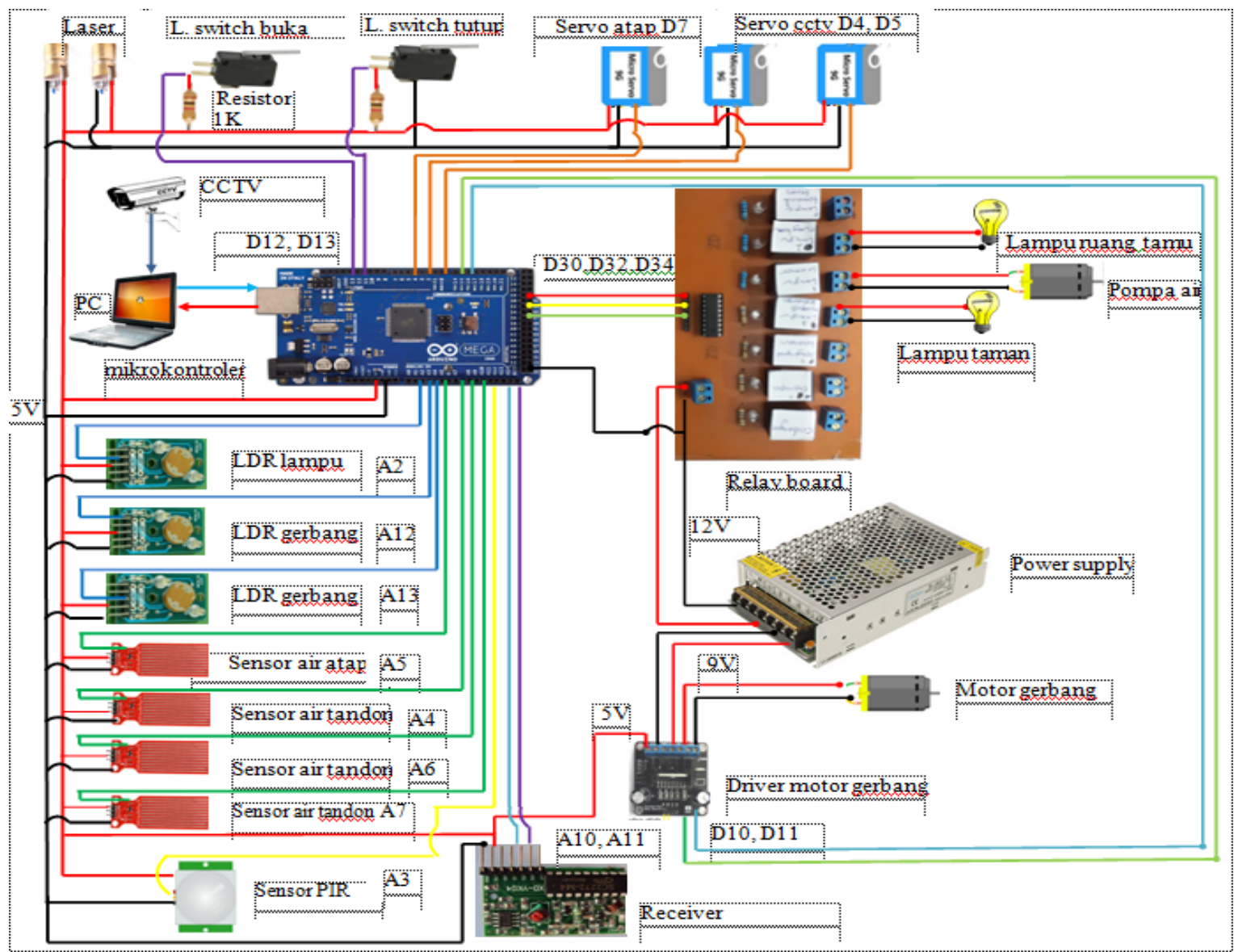

Gambar 4. Diagram desain hardware model smart house. 


\subsection{Sistem Kerja Model Smart House}

Pada smart house system, faktor keamanan termasuk unsur yang sangat penting. Gerbang otomatis akan dirancang untuk menunjang faktor keamanan. Gerbang hanya dapat dibuka dengan menggunakan remote control yang sudah diberi password. Selain itu, pagar dilengkapi dengan kamera CCTV. Ini berbeda dengan rumah-rumah pada umumnya dimana buka tutup gerbang menggunakan cara manual dan mengunci dengan gembok atau alat keamanan sejenisnya. Selain itu, efisiensi penggunaan lampu listrik juga menjadi prioritas. Rencana lampu teras dan lampu taman kita atur bekerja pada jam yang kita inginkan yaitu jam $17.00-06.00$, sedangkan untuk jam $06.00-17.00$ akan menyala ketika situasi sangat mendung (kurang cahaya). Untuk mengetahui situasi mendung atau tidak, peneliti menggunakan sensor $L D R$ yang akan ditempatkan pada ruang terbuka. Ini sesuai dengan prinsip smart house system yaitu efisiensi energi. Sedangkan rumah-rumah pada umumnya lampu akan menyala ketika dihidupkan secara manual dan kadang akan hidup terus-terusan ketika kita lupa mematikan lampu tersebut. Selain lampu teras, lampu ruang keluarga juga menjadi target dimana lampu ruang banyak digunakan setiap rumah. Lampu ini akan kita atur bekerja menurut jam yang kita inginkan yaitu jam 17.00 - 23.00 dimana akan menyala ketika mendeteksi adanya gerakan di ruang tersebut. Untuk mengetahui ada gerakan atau tidak, peneliti akan menggunakan sensor gerak yang akan di tempatkan pada ruang keluarga tersebut. Ketika lebih dari jam 23.00 maka lampu akan mati secara otomatis dan tidak akan menyala walaupun ada gerakan. Lampu dapat menyala tetapi dengan cara manual.

Selanjutnya, tidak semua rumah memiliki mesin cuci yang dilengkapi pengering, sedangkan trend masyarakat saat ini suami istri sama-sama bekerja di luar rumah. Oleh sebab itu, agar jemuran pakaian dapat kering tanpa pusing ada hujan maka jemuran otomatis sebagai solusinya. Jemuran otomatis ini akan menutup secara otomatis ketika mendeteksi terjadi hujan. Untuk mendeteksi adanya hujan, peneliti akan menggunakan sensor air. Ini sesuai dengan prinsip smart house system yaitu memberikan rasa kenyamanan, dimana penghuni rumah tidak akan khawatir meninggalkan jemuran walapun akan hujan. Fitur selanjutnya adalah pengaturan pompa air otomatis. Air merupakan kebutuhan vital untuk kebutuhan mandi, masak, mencuci, dan lain-lain. Oleh sebab itu pasokan air harus tersedia di rumah. Banyak rumah yang menggunakan 2 tandon (tangki) air yaitu tandon bawah untuk menampung air dari PDAM dan tandon atas untuk menampung air dari pompa tandon bawah yang selanjutnya dialirkan ke bak mandi atau dapur dengan prinsip gravitasi. Penelitian ini merancang sistem penyalaan pompa air agar jangan sampai pompa menghisap tangki kosong sehingga pompa akan cepat rusak dan pemborosan energi listrik. Peneliti akan menggunakan sensor air untuk mendeteksi level ketinggian air di dalam tandon.

\section{HASIL DAN PENGUJIAN SMART HOUSE SYSTEMS}

\subsection{Display HMI Smart house Systems}

\subsubsection{Display HMI Gerbang Otomatis}

Prinsip kerja pintu gerbang otomatis pada smart house ini yaitu dengan menekan tombol pintu pagar pada HMI atau dengan menggunakan remote untuk membuka maupun menutup gerbang. Display HMI CCTV dan pintu gerbang ditunjukan pada Gambar 5 .
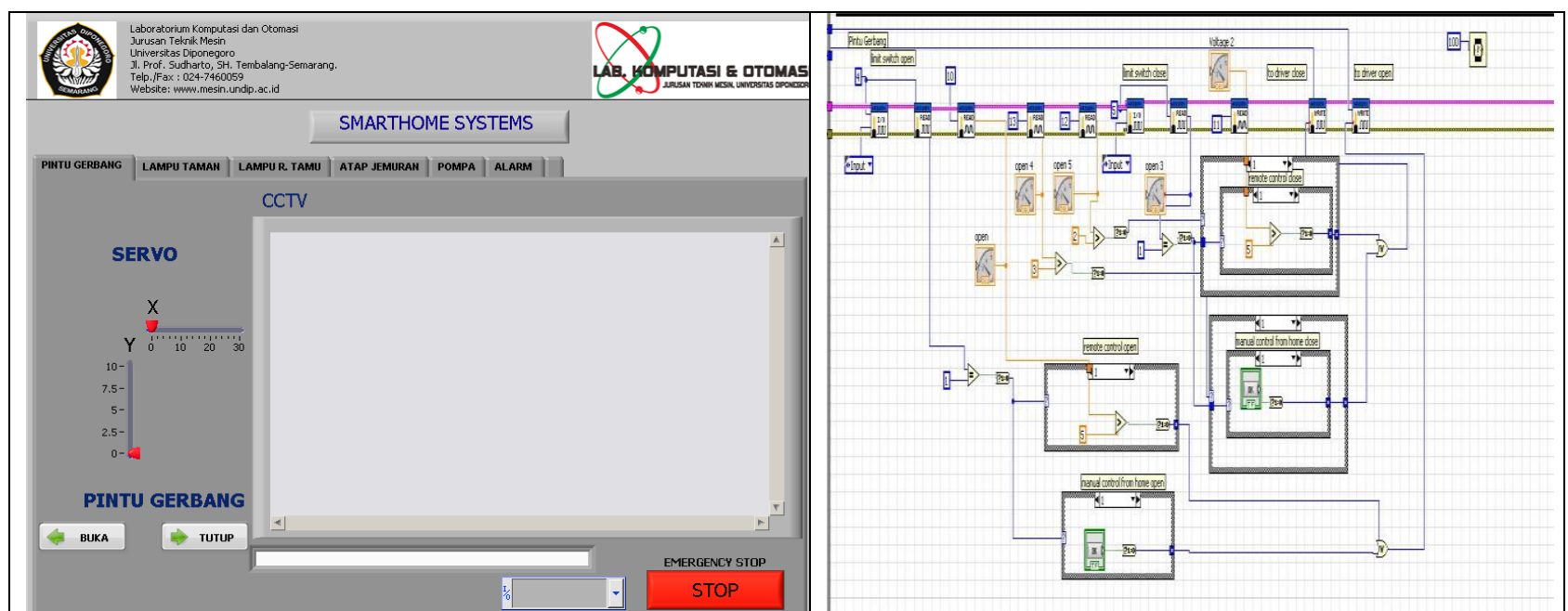

Gambar 5. Display HMI CCTV dan pintu gerbang

\subsubsection{Display HMI Lampu Teras dan Lampu Taman}

Untuk prinsip kerja lampu teras dan lampu taman otomatis pada smart house ini yaitu pada pukul 17.00-05.00 lampu menyala sedangkan pukul 05.00-17.00 akan menyala ketika sensor cahaya tidak mendeteksi adanya cahaya. Selain itu lampu juga dapat menyala secara manual untuk kondisi tertentu. Display HMI lampu teras dan lampu taman ditunjukan pada Gambar 6. 


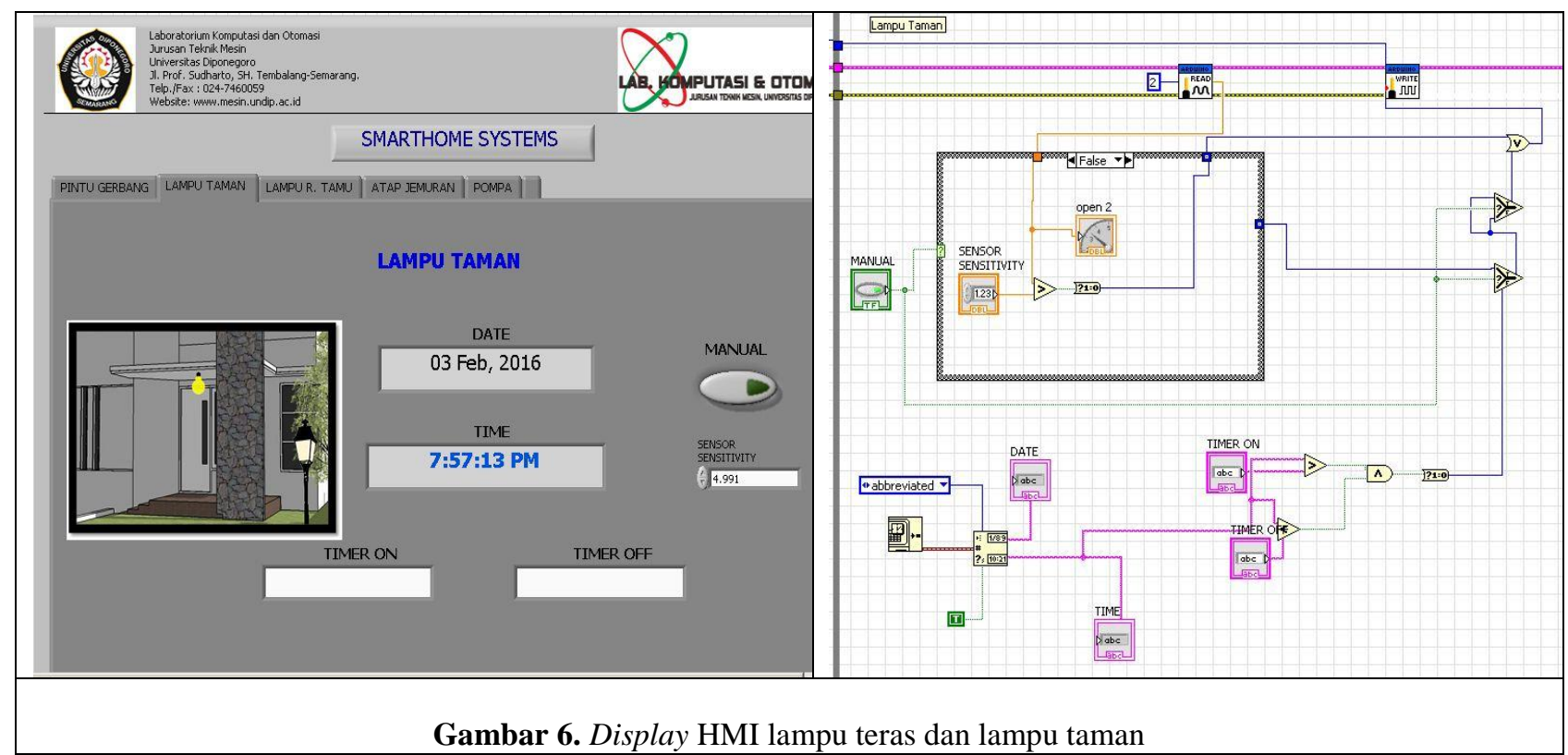

\subsubsection{Display HMI Lampu Ruang Tamu}

Pengaturan kerja lampu ruang keluarga otomatis pada smart house ini yaitu pada pukul 23.00-17.00 lampu mati sedangkan pukul 17.00-23.00 akan menyala ketika sensor gerak mendeteksi adanya gerakan. Selain itu lampu juga dapat menyala secara manual untuk kondisis tertentu. Display HMI lampu ruang tamu ditunjukan pada Gambar 7.

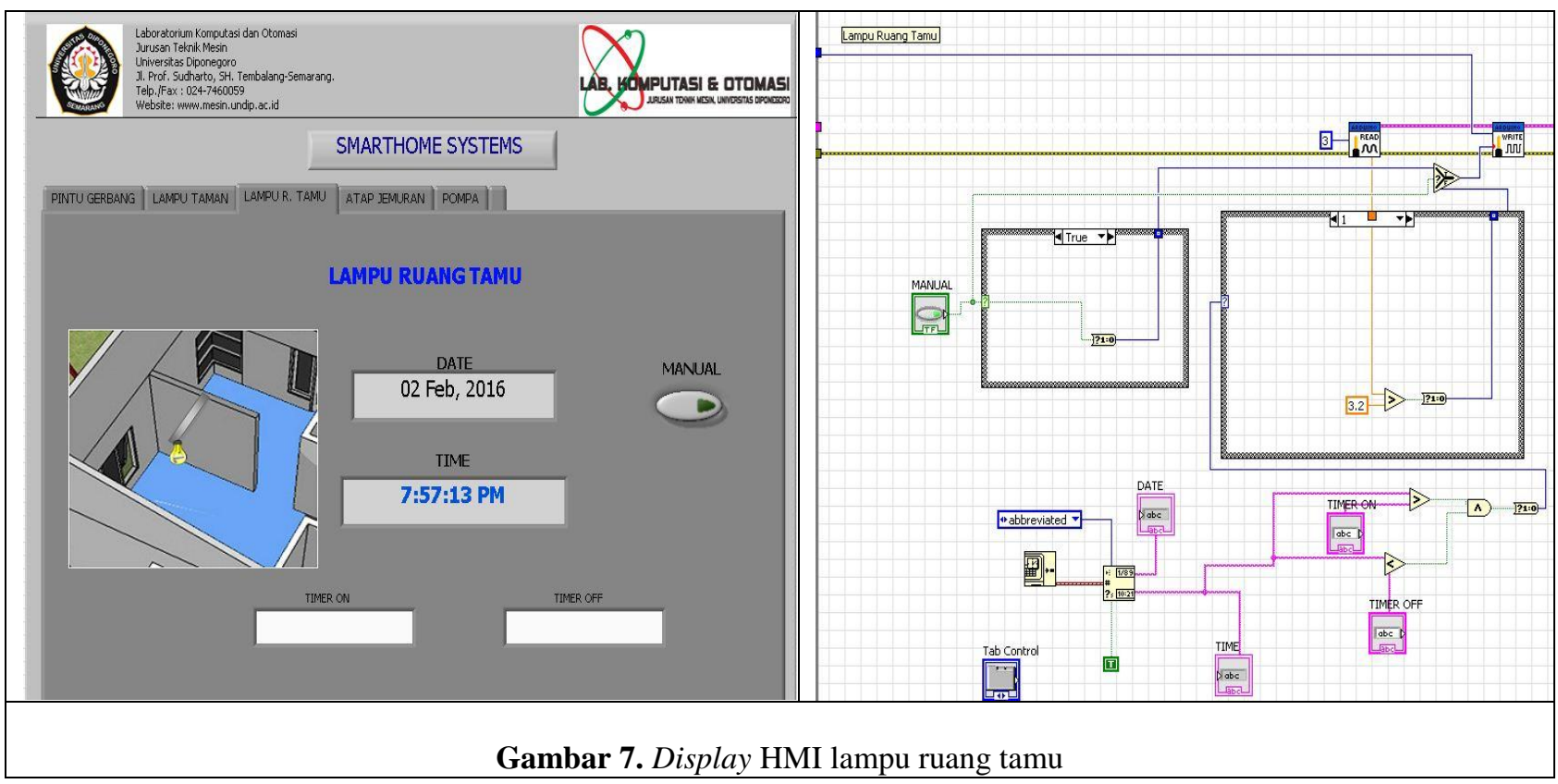

\subsubsection{Display HMI Pompa Otomatis}

Prinsip kerja pompa otomatis adalah pompa akan hidup saat kedua sensor radar yang terletak di tandon atas tergantung di udara dan sensor radar di tandon bawah terendam air. Pompa akan mati saat kedua sensor radar yang terletak di tandon atas terendam air atau saat sensor radar di tandon bawah tergantung di udara. Pompa akan tetap mati meskipun kedua sensor radar yang terletak di tandon atas menggantung di udara apabila sensor radar di tandon bawah menggantung di udara. Hal ini memberikan keamanan pada pompa agar tidak menghisap tangki kosong. Display HMI pompa otomatis ditunjukkan pada Gambar 8. 


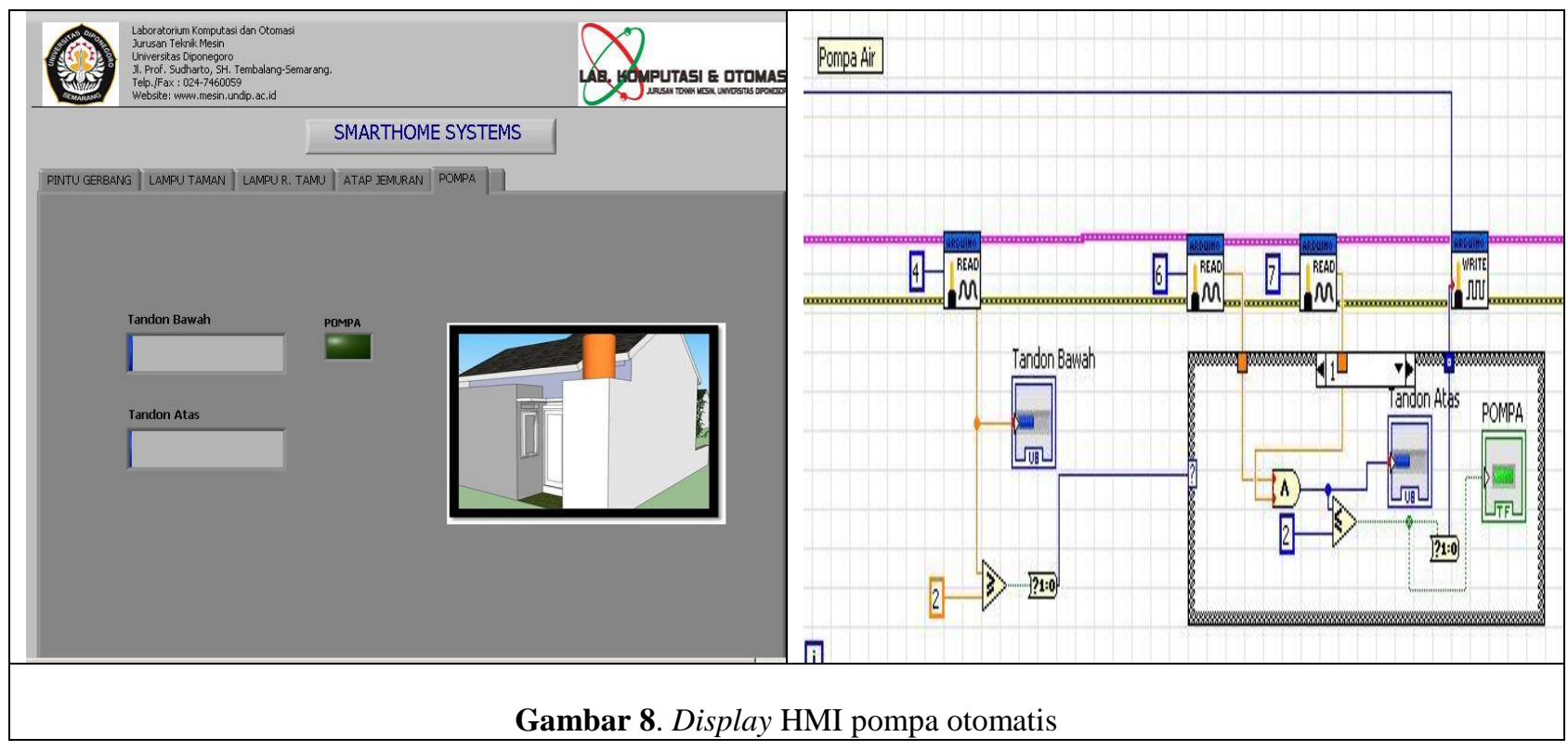

3.1.5. Display HMI Atap Jemuran Otomatis

Cara kerja atap jemuran otomatis otomatis pada smart house ini yaitu atap akan menutup ketika sensor hujan mendeteksi adanya air dan akan membuka ketika tidak mendeteksi air. Display HMI atap jemuran otomatis ditunjukkan pada Gambar 9.
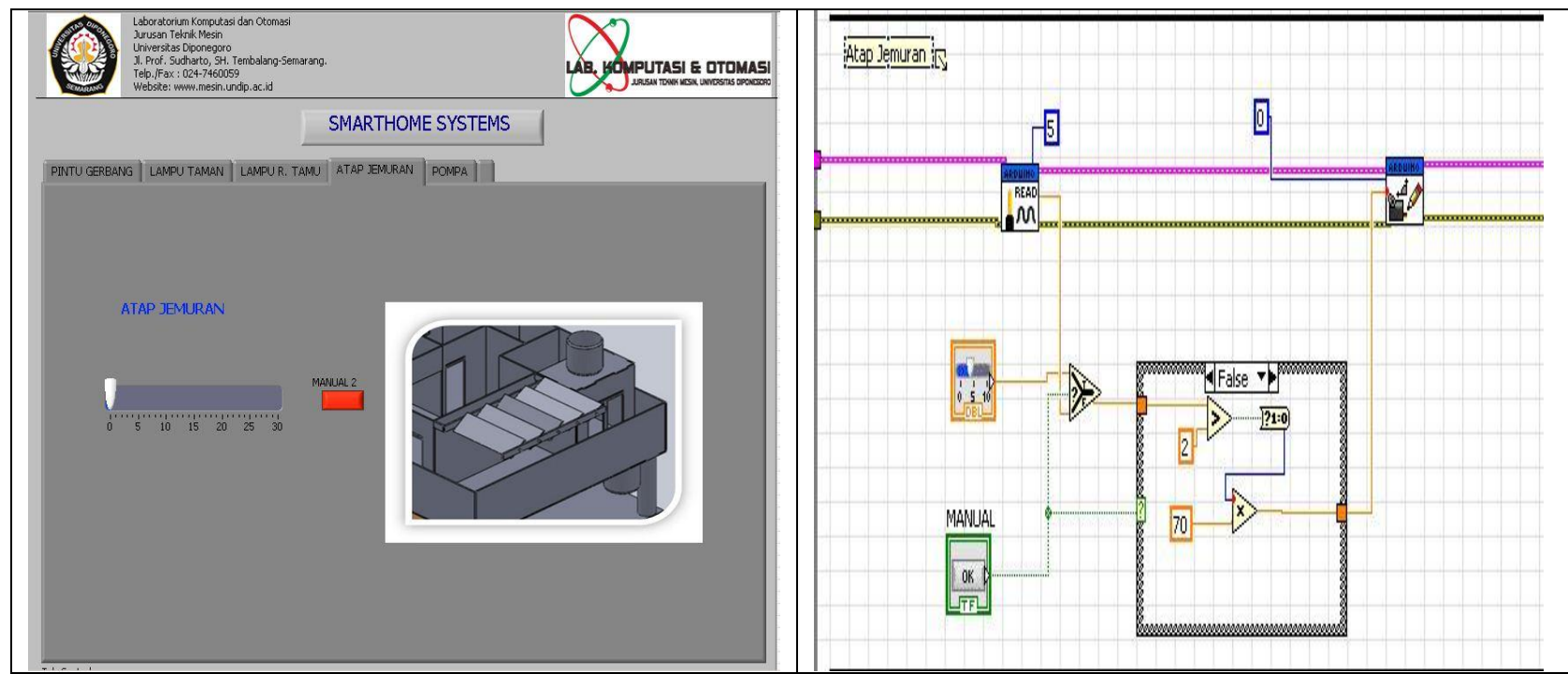

Gambar 9. Display HMI atap jemuran otomatis

\subsection{Estimasi Penghematan Penggunaan Listrik}

Estimasi penghematan energi listrik ini diperoleh dengan membandingkan penggunaan listrik pada smart house dengan penggunaan listrik pada rumah biasa. Pada smart house lampu-lampu dan pompa air dapat menyala dan mati tepat waktu karena dapat diatur waktu aktifnya dengan menggunakan HMI dan dapat aktif juga secara otomatis. Perbandingan perhitungan penggunaan listrik pada smart house dengan rumah biasa ditunjukkan pada Tabel 1 dan 2.

Tabel 1. Penggunaan listrik pada smart house

\begin{tabular}{lllllllll}
\hline No. & Peralatan & Jumlah & $\begin{array}{c}\text { Daya } \\
\text { (watt) }\end{array}$ & $\begin{array}{c}\text { Waktu } \\
\text { (jam) }\end{array}$ & Kwh & $\begin{array}{c}\text { Rp/Kwh } \\
\text { (Rp) }\end{array}$ & Perhari & Perbulan \\
\hline 1. & Lampu taman & 2 & 12 & 11 & 0,264 & Rp.1.509 & Rp.398 & Rp.11.940 \\
2. & Lampu r. tamu & 1 & 12 & 6 & 0,072 & Rp. 1.509 & Rp. 108 & Rp. 3.240 \\
3. & Pompa air & 1 & 350 & 2 & 0,7 & Rp. 1.509 & Rp. 1.056 & Rp.31.680 \\
\hline & Jumlah & & & & & Rp. 1.562 & Rp.46.860 \\
\hline
\end{tabular}


Tabel 2. Penggunaan listrik pada rumah biasa

\begin{tabular}{lllllllll}
\hline No. & Peralatan & Jumlah & $\begin{array}{c}\text { Daya } \\
\text { (watt) }\end{array}$ & $\begin{array}{c}\text { Waktu } \\
\text { (jam) }\end{array}$ & Kwh & $\begin{array}{c}\text { Rp/Kwh } \\
\text { (Rp) }\end{array}$ & Perhari & Perbulan \\
\hline 1. & Lampu taman & 2 & 12 & 12 & 0,288 & Rp.1.509 & Rp.434 & Rp.13.020 \\
2. & Lampu r.tamu & 1 & 12 & 7 & 0,084 & Rp.1.509 & Rp.126 & Rp. 3.780 \\
3. & Pompa air & 1 & 350 & 3 & 1,05 & Rp.1.509 & Rp. 1.584 & Rp.47.520 \\
\hline & Jumlah & & & & Rp.2.144 & Rp.64.320 \\
\hline
\end{tabular}

Setelah mengetahui perbandingan daya yang digunakan untuk menjalankan fitur-fitur rumah pada model smart house systems dan rumah biasa di atas maka kita dapat menghitung efisiensi rumah dengan model smart house systems dari rumah biasa.

$$
\begin{aligned}
& \mu=\frac{\text { Daya total pada smarthome systems }}{\text { Daya total rumah biasa }} \times 100 \% \\
& \mu=\frac{0,264 \mathrm{Kwh}+0,072 \mathrm{Kwh}+0,7 \mathrm{Kwh}}{0,288 \mathrm{Kwh}+0,084 \mathrm{Kwh}+1,05 \mathrm{Kwh}} \times 100 \% \\
& \mu=72,8 \%
\end{aligned}
$$

Sehingga efisiensi rumah model smart house systems dibanding dengan rumah biasa yaitu 27,2\%. Pada model smart house ini hanya menggunakan jumlah lampu yang terbatas, akan tetapi pada kenyataannya jumlah lampu yang digunakan pada bangunan rumah nyata biasanya mempunyai jumlah lampu yang lebih banyak. Oleh sebab itu tentunya nilai efiesiensi penghematan energi akan banyak diperoleh sehingga pengeluran atau penggunaan energi listrik jelas akan berkurang.

\section{KESIMPULAN}

Berdasarkan hasil pemodelan smart house systems berbasis mikrokontroler Arduino Mega 2560 menggunakan LabView, maka penulis dapat mengambil kesimpulan bahwa berhasil membuat model smart house systems dengan skala 1:35 dari ukuran sebenarnya $10 \times 17$ m yang dibuat menggunakan aclyric. Penggunaan software LabView mampu sebagai Human Machine Interface yang terintegrasi dengan smart house systems untuk mempermudah penggunaanya, selain itu sistem HMI dan sensor yang terpasang pada smart house dapat menghemat penggunaan listrik, karena waktu penggunaanya dapat diatur sesuai jam dan kondisi tertentu. Berdasarkan hasil uji coba perbandingan pemakaian energi model smart house systems dengan rumah biasa melalui asumsi-asumsi yang telah ditentukan, dapat menghemat sebesar $27,2 \%$ dibanding dengan rumah biasa.

\section{REFERENSI}

[1] Hamed, B., 2012, “Design and Implementation of Smart House Control using LabView”, International Journal of Soft Computing and Engineering (IJSCE), 1 (6), 98-106.

[2] Sarode, C., Thakar, H.S., 2013, "Intelligent Home Monitoring System", International Journal of Engineering Research and Applications (IJERA), 03 (1), 1446-1450.

[3] Bangali, J., Shaligram, A., "Energy Efficient Smart Home Based on Wireless Sensor Network using LabVIEW", American Journal of Engineering Research (AJER), Vol. 02 (12), 409-413.

[4] King, N., 2003, "Smart Home - A Definition”, Milton Keynes: Intertek Research \& Testing Center.

[5] Janjic, D., 2010, "Smart Home Automation as Part of the Smart Grid", Dubai: Schneider Electric Buildings Business.

[6] Alan, Y., "Reconstruction of Smart Home System: Eliminated Function-oriented Sustainable Development", www.linkedin.com/pulse/reconstruction-smart-home-system-eliminated-sustainable-alan-yang, diakses: 22 September 2016.

[7] Ricquebourg, V., Menga, D., Durand, D., Marhic, B., Delahoche, L., Loge, C., 2006, "The Smart Home Concept: Our Immediate Future", $1^{\text {st }}$ IEEE International Conference on ELearning in Industrial Electronics, 23 28.

[8] Nunes, R., Delgado, J., 1998, “An Architecture for an Home Automation System”, IEEE International Conference on Electronics, Circuits and Systems, 01, 259 - 262.

[9] Marano, V., Rizzoni, G., 2008, "Energy and Economic Evaluation of PHEVs and Their Interaction with Renewable Energy Sources and the Power Grid", Proceedings of the 2008 IEEE International Conference on Vehicular Electronics and Safety, $84-89$. 